$\pi_{e}(H)$, 当且仅当 $G \cong H$. 换言之, $h\left(\pi_{e}(H)\right)$ $=1$.

(2) 若 $\pi_{e}(G)=\pi_{e}\left(S_{8}\right)$, 则 $G$ 为不可解且 $G / O_{2}(G) \cong A_{8}, S_{8}$ 或 $J_{2}$, 其中 $\left|O_{2}(G)\right|=2^{6 k}$. 进一步, 对每一正整数 $k$, 存在满足条件的群 $G$, 使得 $G / O_{2}(G) \cong A_{8}$.

问题 1 对 $q=p^{k} \geqslant 5, p$ 为素数, $k \geqslant$ $1, G=A_{q}$ 是否可由集 $\pi_{e}(G)$ 刻划? 即是否 $h\left(\pi_{e}\left(A_{q}\right)\right)=1$ ?

问题 2 是否存在一个整数 $n>7$ 使 得 $S_{n}$ 能由. $\pi_{e}\left(S_{n}\right)$ 刻划? 如果存在, 这样的最 小的 $n$ 是多少?

在定理的证明过程中,下述引理的证明 使用了计算机和 CAYLEY 语言.
引理 1 设 $G$ 是有限群, $N$ 是 $G$ 的指 数为 4 的正规子群. 如果 $G / N$ 含有同构于 $L_{3}(2)$ 的子群, 则 $\{8,14\} \cap \pi_{e}(G) \neq \varnothing$.

\section{参 考 文 献}

[1] Shi Wu-jie, Bi Jian-xing, The Southeast Asian Bull. of Math. , 1992,16(1):81-90.

[2] 毕建行,数学学报; $1990,33: 70-77$.

Cheryl E. Praeger

(Dept. of Math. , The University

of Western Australia, Australia

施武杰

$\left(\begin{array}{c}\text { 西南师范大学数学系, } \\ \text { 重庆 } 630715\end{array}\right.$

\title{
微机械中的机构学研究方向 *
}

机构学是以运动几何学和力学为主要理 论基础, 以数学分析为主要手段,对各类机构 进行运动和动力分析与综合的学科. 传统的 机构学已由简单机构的运动分析与综合向复 杂机构的运动分析与综合发展, 由机构运动 分析与综合向机构动力分析与综合发展. 近 代的机构学, 研究机构系统的合理组成方法 及判据, 对机构精度进行动态分析, 研究运动 副间隙、摩擦、润滑与冲击所引起的机构运动 变化、稳态与非稳态下的动态响应和过渡过 程问题; 研究考虑构件弹性变形的运动弹性 动力学问题; 研究视整个机构系统为柔体的 多柔体系统动力学和逆动力学分析、综合及 控制问题.

80 年代兴起的微型机械研究领域为机 构学提出了许多新的研究课题. 微型机械不 能简单的理解为传统机械的微型化, 而是远 远超出了传统机械的概念和范畴, 更紧密地 与微电子学相结合, 且涉及到光学、气动力 学、流体力学、热力学、声学、磁学、自动控制、 材料乃至其它我们未知的领域, 它是一门多 学科的综合技术, 具有体积小、重量轻、性能
稳定、耗能低、集成度高等特点. 作为基础学 科的机构学在这一领域是大有用武之地的.

微机械机构学研究方向

(1)机构的组成原理 : 即组成微机械系统 主结构的选择方法及组成方式. 微型机器人 （包括微机械手、微步行机及两者合二为一） 被预测为有很好的应用前景而一开始便受到 许多国家研究者的重视. 它作为一个完整的 微机械系统, 可说是基本上包含了现今有关 微机械研究的各个领域. 所以说选择何种主 结构 (即几个自由度,结构型式,机构原理)的 微型机器人是必须开展的一个研究方向.

(2) 微机械材料的选择: 通过对可作为微 机械构件的材料的物理性能乃到化学性能的 研究,为微机械机构学研究打下基础.

(3)微机械的力学问题: 研究微定位机构 中选择不同材料、不同负载的最佳摩擦力; 研 究运动机构转动和移动副 (包括电机) 摩擦力 和定子、转子间电容、电磁动力学; 研究微机 构与外界物质间的稆附力、工作时机构受力 和动态稳定性.

(4) 摩擦摩损研究:微型机械能耗主要用 
于摩擦力, 其惯性力与之相比, 几乎可以忽略 不计; 而且人们在研究中发现,固有的摩擦理 论和研究方法已不再适合处理微小物体间超 轻载荷的微摩擦问题, 所以开展微摩 擦研究 是不能回避的, 传统的机构动力学分析大多 建立在理论力学的基础上,几乎不考虑摩擦 力的影响, 因而要建立一套新的、适合微型机 械的力学、系统动力学方程就必须开展微摩 擦研究. 这其中包括微摩擦机理及微摩擦的 测量的研究.

(5)微机械系统分析与综合: 包括单个微 机械构件的运动学: 动力学分析与综合, 研究 现有的方法是否适合于微机械系统的分析与 综合, 并与实验结果作比较.

(6)微机械计算机辅助研究: 这是目前开 展微机械机构学研究的有效方法, 它包括单 个微机械构件的运动学及动力学分析与综合 仿真、模块化微机械结构分析与综合、微机械 零件及其总体强构的 CAD、微机械系统的控 制仿真及动态显示.

结合目前的研究进展情况, 可以选择微
型平面连杆机构进行系统的研究,包括: 杆件 材料的选择,材料的物理及机械性能、摩擦摩 损性能研究,具有 1-3 自由度的微机械系统 的组成原理及方法,微机构优化设计方法,运 动学及动力学分析与仿真, 系统动力学方程 的建立与分析,实验结果的比较等.

微机械是一门新兴的高技术学科, 从基 础理论研究走向应用还有相当长的一段路, 需要我们付出更多的努力. 本文根据我们的 研究基础,初步探讨了微机械机构学的研究 方向及方法, 为今后开展这一领域的研究确 定了方向.

\section{参，考 文 献}

［1］王立鼎等, 微机械专集, 光机情报(增刊), 1992.

[2] 干东英,第三届全国机器人学术讨论会论文集(下), 北京, 1991, 484-487.

甘建国王立鼎千东英 (中国科学院长春精密机械研究所,长春 130022)

* 国家自然科学基金资助项目.

\section{$\mathrm{F}^{-}$体系中 $\mathrm{NaZr}_{2}\left(\mathrm{XO}_{4}\right)_{3}(\mathrm{X}=\mathrm{P}, \mathrm{As})$ 的水热晶化 $*$}

自从 Hong 等人发现了 Nasicon 相化合 物 $\mathrm{Na}_{3} \mathrm{Zr}_{2} \mathrm{Si}_{2} \mathrm{PO}_{12}$ 的超离子导电性能以来, 人 们对 Nasicon 及其相关结构的化合物进行了 广泛的研究. 这些化合物也表现出低热膨胀 性能, 可望作为抗热冲击材料和核废料储藏 材料, $\mathrm{NaZr}_{2}\left(\mathrm{XO}_{4}\right)_{3}(\mathrm{X}=\mathrm{P}, \mathrm{As})$ 化合物是这 一大类化合物的母体, 其结构允许化学取代, 从而能够得到许多同构化合物, 这些化合物 通常用固相反应法制备, 较难以得到纯相和 单晶. 我们曾用水热法合成出纯相 $\mathrm{MTi}_{2}$ $\left(\mathrm{PO}_{4}\right)_{3}(\mathrm{M}=\mathrm{Li}, \mathrm{Na}, \mathrm{K})$, 发现水热法优于固 相反应法: $\mathrm{F}^{-}$离子, 作为矿化剂, 对水热晶 化有重要影响, 我们曾在 $\mathrm{F}^{-}$体系中用水热晶 化法生长出较大的完美的沸石单晶. 本文描 述了在 $\mathrm{F}^{-}$体系中用水热晶化法制备出 $\mathrm{NaZr}_{2}\left(\mathrm{XO}_{4}\right)_{3}(\mathrm{X}=\mathrm{P}, \mathrm{As})$ 纯相和较大的单
晶.

水热晶化在内衬有聚四氟乙烯的高压金 内进行. 原料: $\mathrm{ZrOCl}_{2} \cdot 8 \mathrm{H}_{2} \mathrm{O}, 2 \mathrm{~mol} / \mathrm{L}$ $\mathrm{NaOH}, 2.5 \mathrm{~mol} / \mathrm{L} \mathrm{H}_{3} \mathrm{PO}_{4}, 2.8 \mathrm{~mol} / \mathrm{L} \mathrm{H}_{3} \mathrm{AsO}_{4}$ 和 $\mathrm{HF}(40 \%)$. 起始原料按一定的摩尔比在 反应釜内混合. 反应金密封, 放于一定温度 的烘箱中静止晶化 5-7 天, 冷却. 产物过 滤, 洗涤, 干燥, 用 XRPD, IR 和 Raman 光谱 对晶化产物进行表征.

在水热晶化条件: $250^{\circ} \mathrm{C}, 7$ 天, $\mathrm{P}_{2} \mathrm{O}_{5} /$ $\mathrm{ZrO}_{2}=6.4$, 得到纯的, 晶体较小 $(\sim 0.5 \mu \mathrm{m}$ * $0.5 \mu \mathrm{m})$ 的 $\mathrm{NaZr}_{2}\left(\mathrm{PO}_{4}\right)_{3}$. 如果保持其它条件 不变仅将晶化温度由 $250^{\circ} \mathrm{C}$ 降低到 $150^{\circ} \mathrm{C}$, 只 能得到层状化合物 $\alpha-\mathrm{Zr}\left(\mathrm{HPO}_{4}\right)_{2} \cdot \mathrm{H}_{2} \mathrm{O}$. 加 入 $\mathrm{F}^{-}$, 在 $150^{\circ} \mathrm{C}$, 晶化 7 天 $\mathrm{P}_{2} \mathrm{O}_{5} / \mathrm{ZrO}_{2}=6.4$, $\mathrm{F}^{-} / \mathrm{ZrO}_{2}=2$ 的水热条件下, 能够得到纯的较 